\title{
Fundamentals of product family architecture
}

\author{
Jianxin Jiao \\ Nanyang Technological University, Singapore \\ Mitchell M. Tseng \\ The Hong Kong University of Science \& Technology, Hong Kong
}

\section{Keywords}

Product variety,

Customer requirements

\section{Abstract}

Recognizing the rationale of a product family architecture (PFA) with respect to design for mass customization (DFMC), this paper discusses the fundamental issues underlying a PFA, including product information modeling, structural implications of product families, functional variety versus technical variety, class-member relationships inherent in variety, modularity and commonality, PFA design spaces, and PFA

composition. The background research is reviewed in terms of product architecture and modularity, product platform and product families, and product modeling and design process models. To organize product varieties in DFMC, a PFA should be described from three different perspectives, namely the functional (as seen from customer, sales and marketing viewpoints), behavioral (as seen from the product technology or design engineer perspective) and structural (as seen from the fulfillment or manufacturing and logistic perspective). Meeting diverse customer requirements and achieving volume economy simultaneously can be best achieved by synchronizing these three perspectives. In fact, the mappings between PFA views manifest the cooperative effort among different business functions, whilst three PFA views facilitate the integration of different phases of product development.

Received December 1999

Revised May 1999

Accepted September 2000

Integrated Manufacturing

Systems

11/7 [2000] 469-483

(C) MCB University Press

[ISSN 0957-6061]

\section{Introduction}

This research is motivated by an earlier endeavor towards investigating mass customization (Pine, 1993) from a product development perspective, namely DFMC (Tseng and Jiao, 1996). Essentially, the attempt is to include customers in the product life-cycle, particularly in the design phase, through proactively connecting customer needs to the capabilities of a company. The main emphasis is to elevate the current practice of designing individual products to designing product families. To support product customization, a PFA is needed to characterize customer needs and subsequently to fulfill these needs by configuring and modifying well-established modules and components (termed as building blocks). In addition, a PFA performs as an integration platform for extending the traditional boundaries of product design to encompass a larger scope spanning from sales and marketing to distribution and services.

In essence, a PFA defines the underlying architecture of a firm's product platform, within which various product variants can be derived from basic product designs to satisfy a spectrum of customer needs related to various market niches. In other words, a good PFA provides a generic architecture to capture and utilize commonality, within which each new product is instantiated and extends so as to anchor future designs to a common product line structure. In the context of mass customization, the rationale of a PFA resides with not only unburdening the knowledge base from keeping variant forms of the same solution, but also with modeling the design process of a class of products that can widely variegate designs based on individual customization requirements within a coherent framework. Figure 1 illustrates the principle of PFA with respect to DFMC.

The current issue and full text archive of this journal is available at http://www.emerald-library.com

\section{Background review}

2.1 Product architecture and modularity Product architecture can be defined as the way in which the functional elements of a product are arranged into physical units and the way in which these units interact (Ulrich and Eppinger, 1995). It is quite obvious that all products have some kind of architecture, even if it is not necessarily has been considered during the design phase (Lanner and Malmqvist, 1996). The choice of product architecture has broad implications for product performance, product change, product variety, and manufacturability (Ulrich, 1995). Product architecture is also strongly coupled to the firm's development capability, manufacturing specialties, and product strategy (Pimmler and Eppinger, 1994).

Typically, product architecture design occurs during the configuration design stage, that is, after conceptual design but before parametric design (Dixon et al., 1988). Configuration design is the process of synthesizing product structures by determining what components and subassemblies are in the product and how they are arranged spatially and logically. Certainly, product configuration controls a product's fabrication and assembly characteristics. It also controls a product's adaptability necessary to respond to changes in customer requirements.

Often, a product's architecture is thought of in terms of its modules (Ulrich and Eppinger, 1995). A module[1] is a physical or conceptual grouping of components.

Modularity is the concept of decomposing a system into independent parts or modules that can be treated as logical units (Pimmler and Eppinger, 1994). Modularity has been defined as the relationship between a product's functional and physical structures such that:

1 there is a one-to-one or many-to-one correspondence between the functional and physical structures; and

2 unintended interactions between modules are minimized (Ulrich and Tung, 1991; Ulrich, 1995; Erens and Verhulst, 1997). 
Jianxin Jiao and

Mitchell M. Tseng

Fundamentals of product

family architecture

Integrated Manufacturing

Systems

$11 / 7$ [2000] 469-483

\section{Figure 1}

The principle of PFA with respect to DFMC

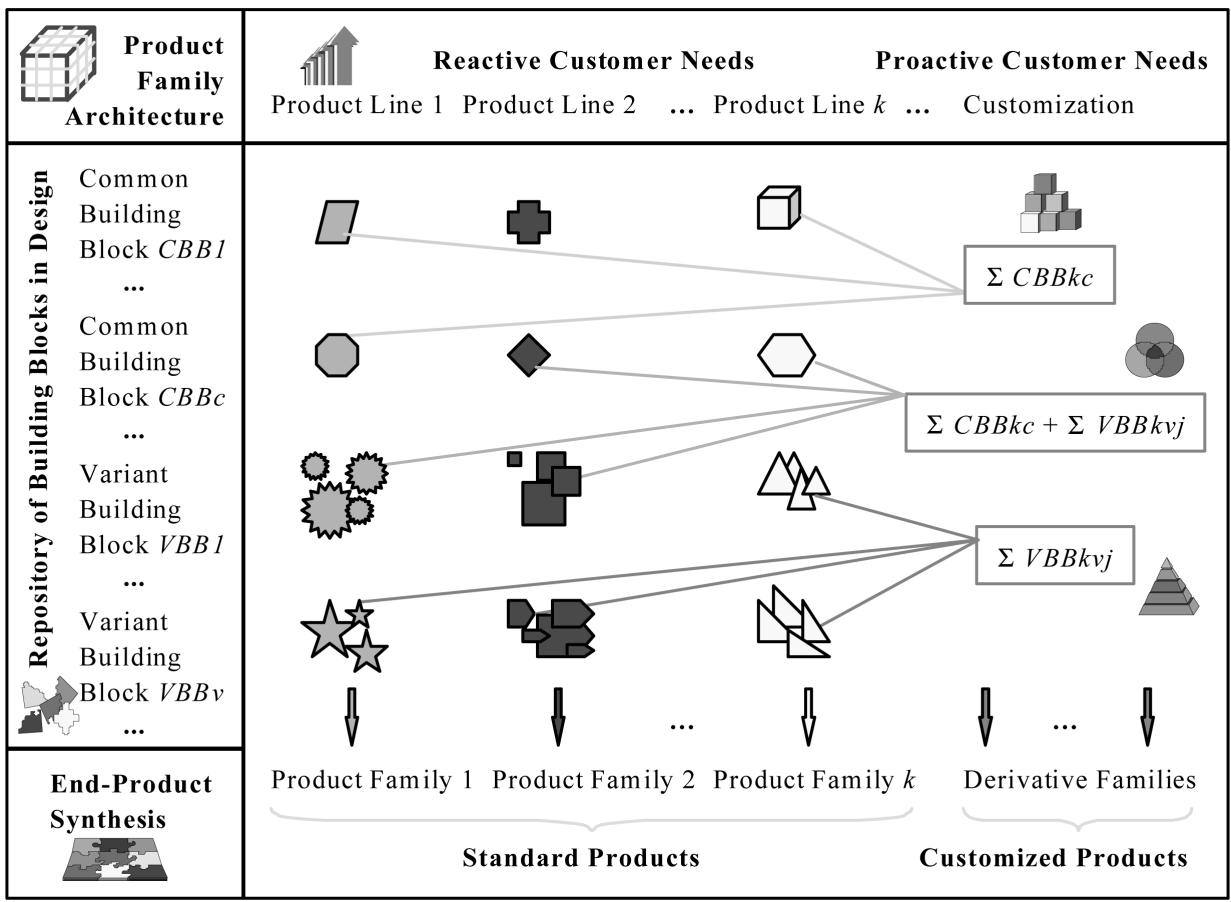

There is some related research regarding decomposition and architecture at the system definition stage of product design. The core research begins with Alexander (1964), who describes a design process that decomposes (or partitions) designs into minimally coupled groups. Simon (1981) continues by suggesting that complex design problems can be described in terms of hierarchical structures consisting of "nearly decomposable systems" organized such that the strongest interactions occur within groups and only weaker interactions occur among (between) groups. Pahl and Beitz (1996) and Suh (1990) build upon these concepts by modeling the functional requirements of product design in terms of exchanges of energy, materials, and signals between functional elements organized in hierarchical functional structures. Pimmler and Eppinger (1994) extend Steward's design structure matrix (DSM) model (1981) to investigate the interaction issues and give considerable insight into product architecture and decomposition. While interactions embody the technical aspects of product architecture (Lanner and Malmqvist, 1996), the economic aspects of product architecture design are dealt with by Erixon et al. (1996) through a method called modular function deployment (MFD). Ulrich (1995) defines several types of product architectures in terms of how the functional elements are mapped onto physical components and relates the strategic importance of architecture choice to firm performance. Henderson and Clark (1990) also point out the importance of architecture by noting that established firms frequently fail when confronted by a novel architecture. Ulrich and Eppinger (1995) provide a methodology for developing product architecture, although interactions are only considered after the architecture is chosen (Pimmler and Eppinger, 1994).

The application of architecture and modularity to design results in modular product design so as to accommodate agile product development (Anderson, 1997). Modular product design refers to designing products, assemblies, and components that fulfill various functions through the combination (configuration) of distinct building blocks (modules) (Pahl and Beitz, 1996; Kusiak and Huang, 1996). From a study of seven companies, Erlandsson et al. (1992) have shown that increased modularity of a product gives positive effects in the total flow of information and material in a company, from development and purchasing to storage and delivery.

Issues associated with modular design include:

1 module creation/identification;

2 interface analysis/evaluation; and

3 module selection/configuration, viz. synthesis. 
Jianxin Jiao and

Mitchell M. Tseng

Fundamentals of product

family architecture

Integrated Manufacturing

Systems

11/7 [2000] 469-483
Pahl and Beitz (1996) stress the importance of functional structures in modular product development by classifying modular function space into basic, auxiliary, adaptive, special, and customer-specified functions.

Karmarkar and Kubat (1987) discuss the module selection problem from an operations research perspective. Kusiak and Huang (1996) present a graphical representation of product modularity and propose a heuristic approach to module identification. Kohlhas and Birkhofer (1996) develop a program system for the computer-aided development of structures for modular systems. Their system focuses on the aspect of modular configuration. Erixon (1996) systematizes procedures for modular product design mainly concerning a matrix of modular function deployment (MFD) and design for manufacturability and assembly (DFMA) analysis. The MFD focuses mainly on the evaluation of module integration. Hillstrom (1994) proposes a method that helps the designer clarify how interfaces between modules influence module functions and to select the best interface location. His method is based on axiomatic design theory (Suh, 1990) and contributes mostly to mechanical part design.

In summary, current practice refers to modules mostly as physical parts or components in the context of manufacturing and assembly that lie in the process domain. Efforts are rarely put on the functional and/ or physical domains of design, especially in terms of systematic planning of modularity starting from early conceptual design stages.

In addition, current research investigates the architecture and modular product design mostly in the context of a single product. Since manufacturing companies increasingly develop product families to offer a large variety of products with limited development and manufacturing costs, the architecture(s) for product families become more and more important (Meyer, 1997). A limited literature has been devoted to addressing issues regarding architecture(s) of product families (Erens and Verhulst, 1997; Ishii et al., 1995a). Ishii et al. (1995a) investigate product family construction through evaluating the costs and value of providing variety whilst the architecture(s) of product families has not been dealt with explicitly. Erens and Verhulst (1997) point out using various product models to describe the architecture(s) of product families. Essentially, they model the architecture(s) of product families as a packaging of single product models, which fails to capture underlying characteristics of product family architecture as different from architectures of individual products.

Fujita and Ishii (1997) point out one important characteristic to discern the architecture of a family of products from that of a single product, i.e. the simultaneous handling of multiple products. The implications of this simultaneity of multiple product variants help us understand and capture the difference between these two types of architectures. While the architecture of a single product is mostly concerned with modularity, this research contends that the product family architecture involves two characteristics of design:

1 the modularity of a product structure; and

2 the commonality among product variants.

This will be elaborated in Section 2.3, together with class-member relationships.

2.2 Product platform and product families

Streams of individual products generated by firms may be thought of as evolving families (Meyer and Utterback, 1993). A product family is defined as a set of products that share common technology and address a related set of market applications (Meyer, 1997). The commonality of technologies and markets leads to efficient and effective manufacturing, distribution, and services, where the firm tailors each general resource or capability to the needs of specific market niches (Pine, 1993).

It has been shown that the individual products can be efficiently constructed on successful generations of underlying product architectures, commonly referred to as a product platform (Wheelwright and Clark, 1992; Meyer and Utterback, 1993). Meyer (1997) defines a product platform as the technological foundation of product families. That is, a platform is the physical implementation of a technical design that serves as the base architecture for a series of derivative products. The platform also embraces manufacturing technologies and processes employed in production. A strong platform provides leveraging of engineering across many products in the sense that each new derivative product can be developed at incremental costs relative to the development of the initial product architecture (Sanderson, 1991).

Actually, the concepts of the product family, platforms, product derivatives, platform architecture are not new. Wheelwright and Clark (1992) differentiate between platforms, their derivative products, and platform extensions for vacuum cleaners. Meyer and Utterback (1993) did the same in their study of electronic imaging 
Jianxin Jiao and

Mitchell M. Tseng

Fundamentals of product

family architecture

Integrated Manufacturing

Systems

11/7 [2000] 469-483 systems and peripherals, as did Sanderson and Uzumeri (1995) in studying the evolution of portable cassette players. Examples of effective product platforms have abounded in industry (Meyer, 1997; Meyer and Utterback, 1993).

Several studies in management are devoted to strategic issues of developing a product platform and/or its managerial impacts on core competencies of a company.

Wheelwright and Sasser (1989) outline a generic product map with emphasis on core products. Meyer (1997) presents a product platform strategy grid for product platform analysis. Product line planning (Page and Rosenbaum, 1987) focuses on product attributes without taking into account engineering concerns. Conjoint analysis (Green and Srinivasan, 1978) is widely used in exploring customer preferences and shedding light on product line rationalization.

In the engineering community, research focuses on more detailed methods of designing product platform and families. Ishii and his group (Ishii et al., 1995a; 1995b; Martin and Ishii, 1996; 1997) develop metrics for evaluating the importance and costs of product variety. Their work is largely based on one-to-one correspondences between functionality and components and assumes product variety as a result of component combination, thus suitable only for dealing with simple products where functional differentiation is directly embodied by specific components, i.e. "seeable" varieties. Essentially, the work ignores the difference between variety of product functionality and that of product components. Fujita and Ishii (1997) commit themselves in design for variety through structuring essential tasks and issues associated with variety design. Their focus is computational approaches to the design process of product families, such as design synthesis, optimization, representation, system constraints, and so forth. As pointed out by Fujita and Ishii (1997; Ishii et al., 1995b), product variety optimization is extremely difficult and far away from practical applications. Mistree's group (Mistree et al., 1993; Simpson et al., 1996a; 1996b) apply goal programming and statistical analysis techniques to design optimization of product families. Similarly, their work focuses on computational support for the design process and excels in parametric design instead of product architecture planning which starts from the conceptual design stage.

In summary, establishing product platforms and families is an important area in both design and manufacturing, where, however, there is a paucity of published work and a lack of good, well-documented and wellstructured case studies (Fujita and Ishii, 1997). This is probably due to the multidisciplinary nature inherent in developing product platforms and families, including design theory, operations management, marketing research, and management of product development (Ulrich, 1995). As a result, in practice, product platforms and product families usually result from haphazard evolution over time, rather than through systematic planning and development (Anderson, 1997).

The strategy of this study of product family design is to emphasize the aspect of information organization and knowledge extraction instead of the design process itself, which is the focus of most current investigations. We believe it is feasible and there is potential to shift efforts from the computation methods of variety synthesis and optimization to developing architectures of product families so as to circumvent difficulties in exploring the design process of product families. This paradigm of problemsolving is similar to the strategy witnessed in artificial intelligence (AI) research, where knowledge processing techniques (Lu, 1990) dominate the exploration of intelligence mechanisms in the human brain.

\subsection{Product modeling and design process models}

During product development, many different product descriptions can be recognized for different business functions and in different phases of development. The descriptions are represented by product models that act as a backbone for combined product information (Krause et al., 1993). The product modeling framework relevant to our work is constituted by the chromosome model (Andreasen, 1992), which is based on the theory of technical systems (Hubka and Eder, 1988), complemented with "genetic"

information that captures the origin of the design characteristics (hence

"chromosome").

In the theory of technical systems, it is stated that four different types of models are needed to describe a technical system and the transformation process that it affects. These are termed as the process, function, organ and component structures, and are said to define the design characteristics of the transformation system. In a design process context, it is also necessary to have a model that states the goals for the design process, i.e. the design specification. The specification and the structures are linked by causal relations: the process determines the 
Jianxin Jiao and

Mitchell M. Tseng

Fundamentals of product

family architecture

Integrated Manufacturing

Systems
11/7 [2000] 469-483

functions, the functions are created by the organs, and the organs are materialized by the components (Andreasen, 1992).

Design process models describe the process of establishing the design characteristics of a design object. Figure 2 illustrates one variant of the "overall" design process model (Andreasen, 1992). Similar models are included in most textbooks on mechanical design (see, for example, Hubka and Eder, 1988; Pahl and Beitz, 1996). According to these authors, the design process can be described as a process in which an abstract problem formulation in terms of a "need", is successively transformed into a manufacturable product description. The process can be divided into a number of major phases in which particular characteristics of the system are established. These phases can be divided into smaller steps where sub-problems are addressed, typically using the general problem-solving approach summarized by Suh (1990). The general problem-solving process includes a problem statement in terms of requirements and objectives, the search for alternative solutions, and the selection of the "best" solution; it leads to decisions that influence subsequent processes. It is only at this level that there is some empirical evidence that this is a reasoning pattern followed by practicing designers. These patterns are effectively described by the theory of domains (Andreasen, 1992). This theory describes the design process in a more flexible way by suggesting that the product chromosome (the set of design characteristics) should be seen as a basic map, on which the process of the design process is charted.

In this research, based on the chromosome model (Andreasen, 1992) and design domains (Suh, 1990), a FBS-view product model and associated design mappings (Figure 3 ) are

\section{$\overline{\text { Figure } 2}$}

A FBS-view product model and design mappings elaborated from the chromosome model (Andreasen, 1992) and design domains (Suh, 1990)

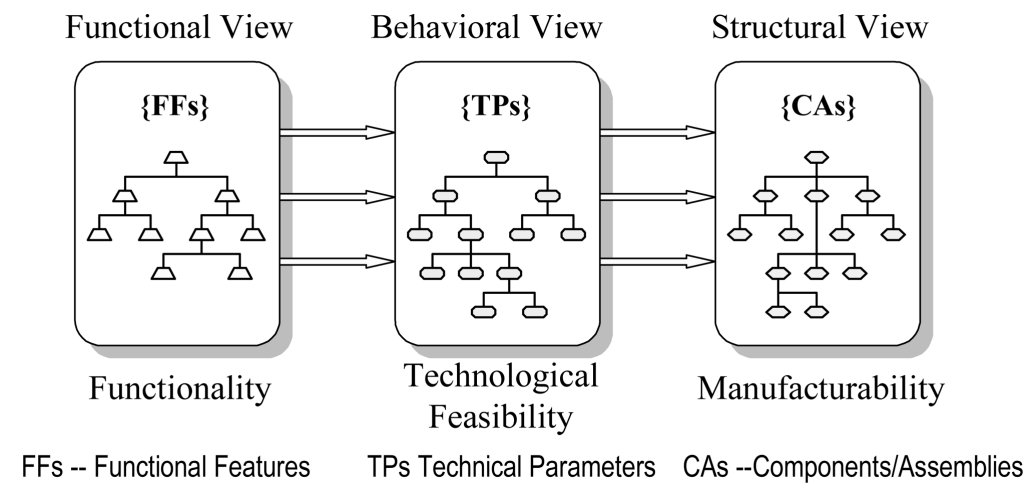

established and employed as the basis of representing a PFA. As illustrated in Figure 2 , a product structure consists of three distinctive views[2], viz. the functional, behavioral and structural (noted as FBS) views. These three views are characterized by functional features (FFs)[3], technical parameters (TPs)[4], and component/ assemblies (CAs)[5] respectively. Each particular view captures a specific aspect of product information, involving functionality (functional structures), technological feasibility (technological solutions/product technologies), or manufacturability (physical structures). The transformation of a technical system (Hubka and Eder, 1988), i.e. the design process, is instantiated by mappings between views that embody the cooperation efforts between different phases of product development.

\section{Product family architecture}

\subsection{Structural implications of PFA}

Based on the understanding of product modeling and the design process presented in Figure 2, a PFA consists of three perspectives, i.e. the functional, behavioral and structural views. As illustrated in Figure 3 , various concerns regarding the PFA, including functionality, technological feasibility, and manufacturability, are dealt with in particular views.

\section{(1) Functional view}

The functional modeling for a single product has been widely investigated, for example structural analysis (Hatley and Pirbhai, 1987) and function structuring (Hundal, 1990). The functional structure of a product consists of the functional elements (Ulrich, 1995), or the so-called functional requirements (FRs) (Suh, 1990), and their interrelationships that involve decomposition and/or dependency (Pahl and Beitz, 1996). In the context of product families and mass customization, the functional structure of a PFA exhibits the product line of a firm that embodies the customer perceptions on its product spectrum (product offerings). The functional merit of a PFA is judged by the capability of its product line structure for customer recognition related to target market niches. A product line structure is therefore referred to as the underlying patterns of customer requirements captured by the product portfolio. More specifically, the functional view of a PFA embodies a product line structure in terms of:

- different customer groups;

- the FFs and their relative importance/ priority for every customer group; and 
Jianxin Jiao and

Mitchell M. Tseng

Fundamentals of product

family architecture

Integrated Manufacturing

Systems

11/7 [2000] 469-483
- the classification of FF instances for customers within each customer group.

While incorporating specific product strategies and business visions, product line structuring usually excludes engineering considerations such as costs and process planning. More issues related to the functional modeling of a PFA include customer segmentation, product strategies, competitor analysis, technological trends, and so on.

\section{(2) Behavioral view}

Corresponding to each customer group identified in the functional view, the behavioral view reveals the application of a technology (i.e. solution principle) to a product design and describes the product design by its modules and the modular structure. A modular structure is referred to as the combination of modules to configure modular products (Kohlhase and Birkhofer, 1996). It describes the subdivision of end products into smaller units and the interconnections (interrelationships) between modules (Pahl and Beitz, 1996), e.g. a circuitry topology in an electronic product design. In the behavioral view, modules and modular structures are defined in terms of technical parameters (TPs) corresponding to specific FFs instead of physical components and assemblies. The purpose is to highlight differentiation (variety) in product design resulting from different solution technologies applied to meet diverse customer needs. The variation (variety) resulting from manufacturing concerns is dealt with by the structural view of the PFA. Issues regarding the technical modeling of a technological

\section{$\overline{\text { Figure } 3}$}

Structural implications and multiple views of a PFA

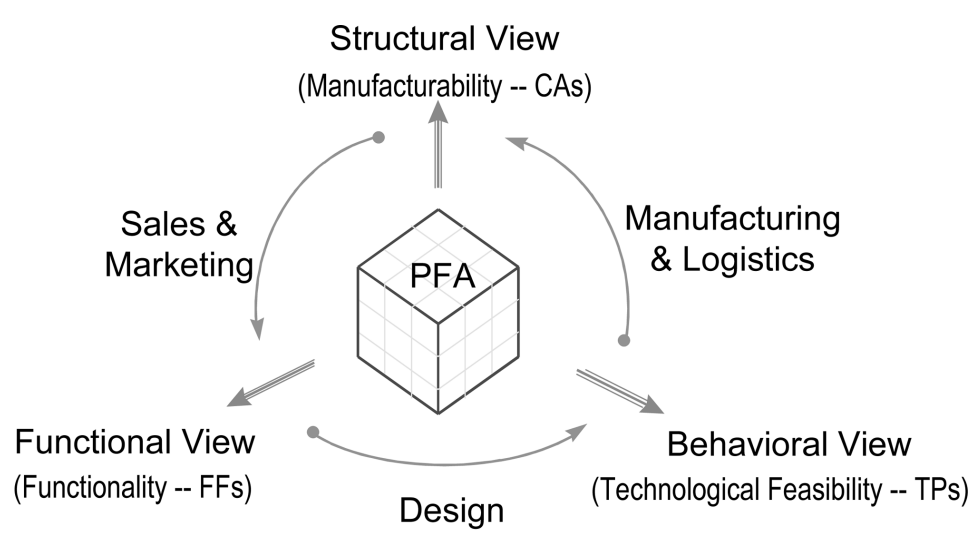

Views -- Integration of different phases of product development Mappings between views -- Integration of different business functions FFs -- Functional Features, TPs -- Technical Parameters, CAs -- Components/Assemblies

solution (product technology) include documenting TPs and the mappings from FFs to TPs; determining technical modules by minimizing design coupling[6]; and establishing modular structures for design synthesis.

\section{(3) Structural view}

The structural view is similar to Eren and Verhulst's physical model (1997). This structural view represents product information by a description of the physical realization of a product design and is strongly related to the construction of the product. Existing process capabilities impose constraints on this realization to guarantee easy manufacturing and assembly operations without compromising the cost and lot-size constraints in order to keep the economy of scale. More specifically, the physical model consists of various types of components and assemblies (CAs) in order to realize technological solutions/product technologies generated in the behavioral view. Apart from mapping relationships of FF-TP-CA, an important concern associated with the structural view is the economic evaluation of granularity tradeoffs among various CA options according to available process capabilities of a firm. This is approached by identifying suitable component clusters, or chunks as Pimmler and Eppinger (1994) called them, and assembly levels across all the products (families) incorporating volume and cost concerns. Moreover, different component modularity strategies, such as component-swapping, component-sharing and bus modularity (Ulrich and Tung, 1991), should be explored in determining configuration structures for end products.

\subsection{Mappings between the views of PFA}

While corresponding to and supporting different phases of product development using a FBS-view product model, the PFA integrates several business functions in a context-coherent framework. This is embodied by the mappings between the three views of a PFA (Figure 3). Various types of customer needs (customer groups) are mapped from the functional view to the behavioral view characterized by solution principles (TPs and modular structures). Such a mapping manifests the design activities. The mapping between the behavioral view and the structural view reflects considerations of manufacturing and logistics, where the modular structure and technical modules in terms of TPs are realized by the physical modules in terms of components and assemblies through incorporating assessments of available process capabilities and the economy of 
Jianxin Jiao and

Mitchell M. Tseng

Fundamentals of product

family architecture

Integrated Manufacturing

Systems

11/7 [2000] 469-483 scale. The sales and marketing functions involve the mapping between the structural view and the functional view, where the correspondence of a physical structure to its functionality provides necessary information to assist in negotiation among the customers, marketers, and engineers, e.g. facilitating the request-for-quotation ( $\mathrm{RFQ}$ ).

\subsection{Functional variety and technical variety}

While facilitating the development of superior products, design for manufacturability methodologies usually address a single product (Prasad, 1996). To move beyond this limitation, a new methodology for product variety is required to optimize product lines across families and generations (Fujita and Ishii, 1997). In order to optimize product variety, however, it is necessary first to classify the types of variety, particularly in terms of the requirements of mass customization, and then develop pertinent design strategies.

Product variety is defined as the diversity of products that a production system provides to the marketplace (Ulrich, 1995). In this research, we assert two types of variety, namely the functional variety and the technical variety. The functional variety is used broadly to mean any differentiation in the attributes related to a product's functionality from which the customer derives a benefit. On the other hand, the technical variety refers to diverse technologies, design methods, manufacturing processes, components and assemblies, etc., that are necessary to achieve some functionality of a product required by the customer. While the functional variety is mostly related to customer satisfaction, the technical variety usually involves manufacturability and costs.

Even though the two types of variety have some correlation in product development, they result in two different design strategies. Since the functional variety directly affects customer satisfaction, this type of variety should be encouraged in product development. Such a design for "functional" variety strategy aims at increasing functional varieties and manifests itself through vast research in the business community, such as product line structuring (Page and Rosenbaum, 1987; Sanderson and Uzumeri, 1995), equilibrium pricing (Choi and DeSarbo, 1994), product positioning (Choi et al., 1990), etc. On the contrary, design for "technical" variety tries to reduce technical varieties so as to gain cost advantages. Under this category, research includes variety reduction program (Suzue and Kohdate, 1990), design for variety (Ishii et al., 1995a; Martin and Ishii, 1996; 1997), design for postponement (Feitzinger and Lee, 1997), design for technology life-cycle (Ishii et al., 1995b), function sharing (Ulrich and Seering, 1990), design for modularity (Erixon, 1996), etc.

Figure 4 illustrates different strategies of design for variety adopted in the PFA. While maintaining functional varieties in the functional view through customer requirement analysis, the PFA tries to reduce technical varieties in the behavioral and structural views by systematic planning of modularity to facilitate plugging in modules that deliver specific functionality.

\subsection{Class-member relationships for variety characterization}

A PFA organizes and represents a variety of objects in different views using class-member relationships. For each type of object corresponding to a particular view, i.e. functional, technical or physical modules, the variety of the object results from two layers. First the objects differentiate in terms of their attribute variables (e.g. FFs or TPs). Different sets of variables distinguish diverse types of objects. Then, for each type of objects (class) defined by a specific set of variables (class attributes), varieties can further result from diverse instances (members) of particular variables. That is, every variable may take on several values. Such a representation using class-member relationships reveals the sources and migration of varieties involved in the three views of the PFA. Table I gives an application example of class-member relationships to variety characterization in the functional view, where a variety class is represented by its attribute variables (FFs), and a variety of members within this class is characterized by different values (instances) of specific variables $\left(\mathrm{FFs}^{*}\right)$.

\subsection{Modularity and commonality in PFA}

There are basically two issues inherent in a PFA, namely modularity and commonality. Table II highlights different implications of modularity and commonality in a PFA, as well as the relation between them.

The concepts of modules and modularity are central in constructing an architecture (Ulrich, 1995). While a module is a physical or conceptual grouping of components that share some characteristics, modularity tries to separate a system into independent parts or modules that can be treated as logical units (Newcomb et al., 1996). Therefore, decomposition is a major concern in modularity analysis. In addition, to capture 
Jianxin Jiao and

Mitchell M. Tseng

Fundamentals of product

family architecture

Integrated Manufacturing

Systems

$11 / 7$ [2000] 469-483

$\overline{\text { Figure } 4}$

Variety leverage: handling variety in mass customization by PFA
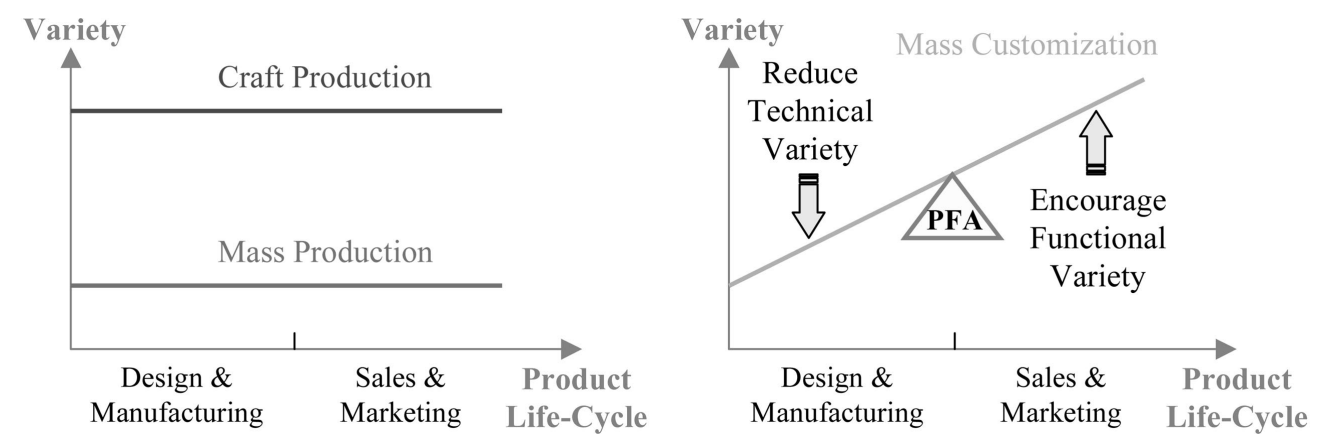

$\overline{\text { Table I }}$

Applying class-member relationships to characterize the derivation of varieties: an example in functional specifications of power supplies

\begin{tabular}{|c|c|c|c|c|c|c|}
\hline \multicolumn{2}{|c|}{ Variety class (FF variables) } & \multicolumn{5}{|c|}{ Variety members (FF instances) } \\
\hline \multicolumn{2}{|c|}{ Customer group 1} & \multicolumn{5}{|c|}{ Customers within group 1} \\
\hline \multicolumn{2}{|c|}{ Specification of product family 1} & \multicolumn{5}{|c|}{ Individual specifications for product variants of family 1} \\
\hline & FF1 = Total power & & $<200 W$ & $>200 \mathrm{~W}$ and $<1,000$ & l $>1,000 W$ & \\
\hline $\multirow[t]{2}{*}{\mathrm{FFs}}_{1}$ & FF2 $=$ Number of outputs & $\left\{\mathrm{FFs}^{*}\right\}_{1}$ & Single & Dual & Triple & $>3$ \\
\hline & $\mathrm{FF} 3=\mathrm{PFC}$ & & No & Yes & & \\
\hline \multicolumn{2}{|c|}{ Customer group 2} & \multicolumn{5}{|c|}{ Customers within group 2} \\
\hline \multirow{2}{*}{\multicolumn{2}{|c|}{ Specification of product family 2}} & \multicolumn{5}{|c|}{ Individual specifications for product variants of Family 2} \\
\hline & FF1 = Total power & & $<100 W$ & $>100 \mathrm{~W}$ and $<500 \mathrm{~W}$ & $>500 \mathrm{~W}$ and $<100 \mathrm{~W}$ & $>1,000 W$ \\
\hline $\multirow[t]{3}{*}{\mathrm{FFs}}_{2}$ & FF2 $=$ Number of outputs & $\left\{\mathrm{FFs}^{*}\right\}_{2}$ & Single & Dual & Triple & $>3$ \\
\hline & FF3 = Safety & & VDE, CSA & UL, VDE & CSA, VDE, UL & UL, CSA \\
\hline & FF4 = Size & & 5"X3"X1.2" & 7"X4.25"X1.8" & 16.5"X5.2"X2.5" & $18 " \times 7.25 " \times 3 "$ \\
\hline
\end{tabular}

and represent product structures across the entire product development process, the PFA achieves its modularity from multiple viewpoints, including functionality, solution technologies, and physical structures. Correspondingly, there are three types of modularity involved in the PFA, i.e. functional modularity, technical modularity, and physical modularity.

What is important in characterizing modularity is the interaction between modules. Modules are identified in such a way that between-module (inter-module) interactions are minimized whereas withinmodule (infra-module) interactions may be high (Ulrich, 1995). Therefore, three types of modularity in the PFA are characterized by specific measures of interaction in particular

\section{Table II}

Modularity and commonality in PFA

\begin{tabular}{lll}
\hline Issues & Modularity & Commonality \\
\hline Focused objects & Type (class) & Instances (members) \\
Characteristic of measure & Interaction & Similarity \\
Analysis method & Decomposition & Clustering \\
Product differentiation & Product structure & Product variants \\
Integration/relation & & Class-member relationship \\
\hline
\end{tabular}

views. As for functional modularity, the interaction is exhibited by the relevance of FFs across different customer groups. Each customer group is characterized by a particular set of FFs. Customer grouping lies only in the functional view and is independent of the other two views, that is, it should be solution-neutral. In the behavioral view, modularity is determined according to technological feasibility of design solutions. The interaction is thus judged by the coupling of TPs to satisfy given FFs regardless of their physical realization in manufacturing. In the structural view, physical interactions derived from manufacturability become the major concern of the physical modularity.

It is commonality that reveals the difference of the architecture of product families from that of a single product. While modularity resembles decomposition of product structures and is applicable to describing module (product) types, commonality characterizes the grouping of similar module (product) variants under specific module (product) types characterized by modularity. Corresponding to the three types of modularity, there are three types of 
Jianxin Jiao and

Mitchell M. Tseng

Fundamentals of product

family architecture

Integrated Manufacturing

Systems

11/7 [2000] 469-483 commonality in three PFA views. Functional commonality manifests itself through functional classification. That is, it clusters similar customer requirements into one class. Similarity is measured by the distance between $\mathrm{FF}$ instances $\left(\mathrm{FF}^{*} \mathrm{~s}\right)$. In the behavioral view, each technical module, characterized by a set of TPs corresponding to a set of FFs, exhibits commonality through clustering similar TP instances ( $\left.\mathrm{TP}^{*} \mathrm{~s}\right)$ by chunks. Instead of measuring similarity in $\mathrm{CA}$ instances $\left(\mathrm{CA}^{*} \mathrm{~s}\right)$, physical instances (instances of CAs for a physical module type) are grouped according to appropriate categorization of engineering costs derived from assessing existing capabilities and estimated volume, i.e. economic evaluation.

The relation between modularity and commonality is embodied in the classmember relationships. A product structure is defined in terms of its modularity where module types are specified. Product variants derived from this product structure share the same module types and take on different instances of every module type. In other words, a class of products (product family) is described by modularity and product variants differentiate according to the commonality between module instances.

Figure 5 illustrates relations of modularity and commonality in PFA development. First, modularity design space is developed. This design space defines viewpoint-specific product modularity, including functional, behavioral, and structural viewpoints. In commonality design space, diverse instances of specific modules are clustered into chunks. The mappings from modularity design space to commonality design space are defined by module instantiation and clustering of module instances. In PFA design space, fragments of modularity and commonality are incorporated from the modularity design space and the commonality design space to assemble a PFA.

\subsection{PFA composition}

While embodying variety through two layers (modularity and commonality) across three views (FBS), a PFA consists of four major components, namely the product line taxonomy, building blocks, configuration rules, and economic evaluation.

\section{(1) Product line taxonomy}

Product line taxonomy represents the patterns of product portfolios, i.e. the interrelationships among product families, end products (variant products) and building blocks. It reflects the specific product strategy and the business vision. Some of the building blocks are organized to form base products that provide common functions to satisfy certain market niches. Building blocks capture commonality for meeting a class of customers so as to maximize repetitions. Thus, end products can be configured by first selecting a base product and then determining the additional building blocks needed. Product line taxonomy is also a primary communication medium between customers and the PFA. With the product

\section{Figure 5}

Modularity and commonality design spaces and their relations in PFA development

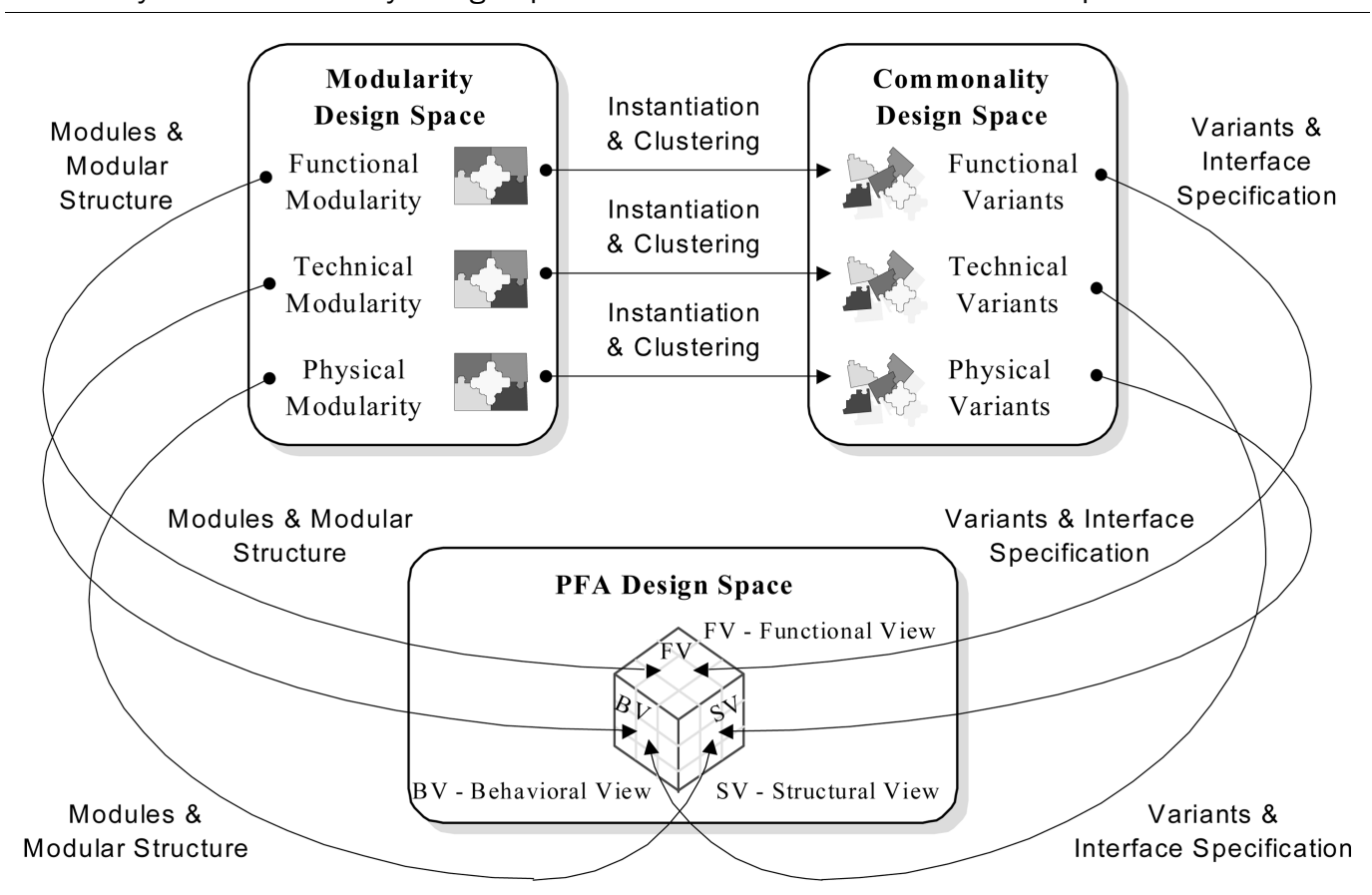


Jianxin Jiao and

Mitchell M. Tseng

Fundamentals of product

family architecture

Integrated Manufacturing

Systems

11/7 [2000] 469-483 line taxonomy, customers can visualize a set of building blocks that will potentially satisfy their individual needs.

\section{(2) Building blocks}

Building blocks are the basic elements of a PFA. They form the basis for reusability and flexibility in configuring variant products. Products can be viewed as a superposition of a number of building blocks. In developing a PFA, the criteria for partitioning building blocks include current and future customer needs, repeatability in design and fulfillment, and ease of configuration. Appropriate levels of granularity are achieved through balancing the reusability and logistic costs.

\section{(3) Configuration rules}

End products are delivered to customers by assembling building blocks according to configuration rules. These rules involve the mapping relationships between customer needs and technical parameters and the compatibility of different building blocks such as the interfaces between building blocks.

\section{(4) Economic evaluation}

Because a PFA provides choices for customers, it is also important that customers are informed about the consequences of their choices with respect to the cost, schedule, and other intangible factors. Economic evaluation can be documented in the form of rules, equations, and tools to help customers to make the necessary tradeoffs.

\section{An application}

A power supply company under our investigation offers various products covering a range of more than 1,200 varieties. Because of the growing varieties, the company is constantly challenged to achieve responsiveness, flexibility, and low costs. There is a significant amount of engineering expense for meeting diverse customer applications. The PFA methodology has been applied as part of the company's practice towards mass customization (Jiao, 1998).

As a type of industrial product, the power supply is a key component in electronic products, such as telephone switching PBX, stereo equipment, computers and instrumentation, etc. Figure 6 illustrates three views of product modeling for power supply design, where the functional, behavioral and structural views are embodied in functional specifications (i.e. functionality), circuitry schematics (i.e. technological solutions/product technologies) and top assemblies (i.e. physical structures) respectively. Such a FBS-view manifestation of product modeling can highlight the particular characteristics of information organization in power supply design that are discussed next.

A power supply can be decomposed into major modules such as the transformer, protection unit, etc. Each module is further broken down into physical sub-modules, such as circuit board, multi-component modules (MCMs), and discrete electronic components.

Various types of modules need to be designed and built in parallel and then correctly matched and assembled into individual power supplies. In the manufacturing process, the circuit board used in the power supply modules is designed and built as an individual component. It requires the layout of the interconnections among components and a series of chemical processes (e.g. etching) that lays down these electronic pathways on the board. A change in circuitry or interconnections at the board level requires that the board be redesigned, laid out, and remanufactured. The manufacturers' choice of the electronics implementation technology is a critical factor in determining manufacturing cost, the flexibility of the manufacturing process in terms of required lead time and the ease of changeovers between designs. These cost decisions are traded off against the functionality provided in terms of speed, the size of the resultant module, and how it fits mechanically into the power supply and the reliability of the system.

The tradeoffs among performance, size, cost, lead time, implementation difficulty, reliability and the resulting adaptation to different models and anticipated, but undefined, changeovers between models create a dilemma for the manufacturer in terms of which technologies to use and how to schedule the changes among the technologies.

The complexity of these information management tasks has led to the development of methodologies for structured organization of product design data to facilitate access, utilization and efficient transfer to manufacturing systems design. A description of this structured design data organization is shown schematically in Figure 7.

As illustrated in Figure 7, product design can be decomposed into physical modules, noted as design instantiation (horizontal axis), such as discrete components and MCMs. Reusing common physical designs promotes efficient product and process evolution as implemented in the group technology. Product designs can also be 
Jianxin Jiao and

Mitchell M. Tseng

Fundamentals of product

family architecture

Systems

11/7 [2000] 469-483
Integrated Manufacturing

decomposed according to functional abstraction, noted as design abstraction (vertical axis), and provide continuity in functional representation between product development phases.

Complex design requires that more abstract levels of representation be used to characterize both physical and functional characteristics of these systems. In electronic design, a well-defined set of these descriptions is used to represent and model functional characteristics. For example, SPICE (Nagel, 1975) is a language developed to model the behavior of individual electronic devices and circuits, and predict the performance of circuits. VDHL is a language developed to represent functionality of digital circuits independent of their physical realizations (Traister, 1997). Electronic schematics are used to describe component interconnections independent of

\section{$\overline{\text { Figure } 6}$}

An illustration of the FBS-view product model in power supply design

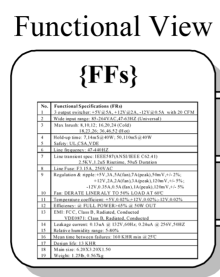

Functionality

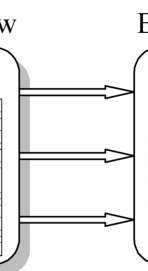

Technological Feasibility

FFs--Functional Specifications
Behavioral View

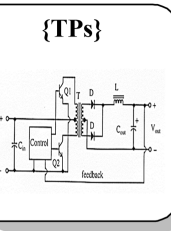

TPs--Circuitry Schematics
Structural View

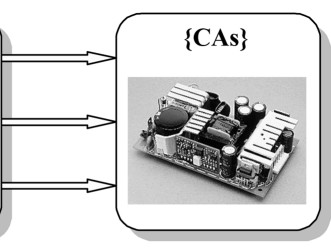

Manufacturability

\section{$\overline{\text { Figure } 7}$}

Abstraction levels of information organization in power supply design

\begin{tabular}{|c|c|c|c|}
\hline \multirow[b]{2}{*}{$\begin{array}{c}\text { Design } \\
\text { Abstraction }\end{array}$} & $\begin{array}{l}\text { Component } \\
\text { Performance } \\
\text { Models }\end{array}$ & $\begin{array}{l}\text { Logic } \\
\text { Models }\end{array}$ & $\begin{array}{c}\text { Functional } \\
\text { Diagrams }\end{array}$ \\
\hline & $\begin{array}{c}\text { Component } \\
\text { Behavioral } \\
\text { Models }\end{array}$ & $\begin{array}{c}\text { MCM } \\
\text { Behavioral } \\
\text { Models }\end{array}$ & $\begin{array}{c}\text { Circuit } \\
\text { Schematic } \\
\text { Diagram }\end{array}$ \\
\hline \multirow[t]{2}{*}{$\begin{array}{r}\text { Physical } \\
\text { Realization }\end{array}$} & $\begin{array}{c}\text { Discrete } \\
\text { Electronic } \\
\text { Components }\end{array}$ & $\begin{array}{c}\text { Multi- } \\
\text { Component } \\
\text { Modules } \\
\text { (MCMs) }\end{array}$ & $\begin{array}{c}\text { Top } \\
\text { Assemblies }\end{array}$ \\
\hline & \multicolumn{2}{|l|}{ Components } & Systems \\
\hline
\end{tabular}

Design Instantiation their component realizations (Ulrich, 1995).

Signal flow diagrams describe signalprocessing functions independent of specific circuit design (Ulrich and Seering, 1989).

We can look at the way that different functionalities might be achieved among distinct models or different generations of the product. These variations are achieved by altering the nature of the circuit and, therefore, altering either the PCB, the components or the choice of MCMs or the choice of gate array, ASIC or custom VLSI technology. A typical electronic subsystem will include a mix of all of these different technologies and distinct models and functional components within the subsystem.

Table III highlights the tasks and methods related to PFA development. In general, PFA development takes place in two layers that deal with different aspects of a PFA. First, a variety of product structures are investigated through systematic planning of modularity in three consecutive views, i.e. functional modularity, technical modularity, and physical modularity. Such a modularity analysis yields modules and modular structures in three views. As a whole, the results comprise the architecture for configuration of modular product design. Then in the commonality layer, for each module identified in the first layer, commonality is studied according to various instances of this module (type). Similar instances are clustered to form a group (variant) represented by a base value plus its variation range. The linkage between two layers is manifested through class-member relationships in between. While the objects in the modularity layer are module types (classes), the objects in the commonality layer are instances of specific module types. Details of key techniques adopted in PFA development are described in Jiao (1998).

\section{Discussions}

While mass customization is discussed mostly for consumer products (Baker, 1989; Kolter, 1989; Sanderson and Uzumeri, 1995; Meyer and Utterback, 1993), this research asserts the necessity to emphasize those industrial products, such as power supply products, that pose a few challenges in both design and manufacturing as well as in marketing. The assumptions associated with the market and engineering practice for industrial products are observed as follows.

\section{(1) Industrial marketing}

The market for industrial products has the following features that make customer requirement analysis easier: 
Jianxin Jiao and

Mitchell M. Tseng

Fundamentals of product

family architecture

Integrated Manufacturing

Systems

11/7 [2000] 469-483
- Customers of industrial products usually have more knowledge of products than those of consumer products. Therefore, customers of industrial products can offer more definite information concerning their needs.

- In the market of industrial products, purchase decision making is conducted by concrete factors such as product performance and product costs rather than abstract factors such as aesthetic and ergonomic criteria.

- Since the number of customers is comparatively limited and customers can often be specified in the market for specific industrial products, a survey of market needs can easily be conducted with acceptable accuracy.

\section{(2) Variant product development}

The engineering practice of industrial products manifests itself through more incremental than innovative development (Marston et al. 1997). That is, variant design is frequently adopted in practice to evolve from existing products, instead of designing a product from scratch. It is reported that up to 25 percent of design activity is dedicated to variant design where configurations are largely predetermined and design freedom is limited, or at least constrained by existing solutions (Pahl and Beitz, 1996). The advantages lie in the utilization of the learning from historical data, warranty information, customer feedback, installation, and service records, etc. so as to enhance product features and reduce development efforts.

\section{(3) High technological content}

An increasing trend in technological content has been witnessed in most products, especially for industrial products. The complexity of industrial products stems from not only advanced manufacturing processes but also from the application of solution technologies. Actually, quickly increased product differentiation is the result of the use of advanced technologies plus the combination of diverse technologies in one system. Therefore, the FBS-view product modeling approach (Figure 3) is most appropriate for industrial products.

\section{Conclusions}

This paper asserts to describe a PFA from three perspectives, namely the functional, behavioral and structural views. In fact, most

\section{$\overline{\text { Table III }}$}

Tasks and methods associated with PFA development

\begin{tabular}{|c|c|c|c|c|}
\hline \multirow{2}{*}{$\begin{array}{l}\text { Issues in PFA } \\
\text { development }\end{array}$} & \multicolumn{3}{|c|}{ PFA } & \multirow{2}{*}{$\begin{array}{l}\text { Product } \\
\text { families }\end{array}$} \\
\hline & Functional view & Behavioral view & Structural view & \\
\hline (1) Modularity & Functional modularity & Technical modularity & Physical modularity & \\
\hline Modules & Functional modules & Technical modules & Physical modules & \\
\hline Module variables & $\mathrm{M}_{\mathrm{Fi}}=\{\mathrm{FFs}, \mathrm{Ws}\}$ & $\mathrm{M}_{\mathrm{Tj}} \subset\{\mathrm{TPs}\}$ & $M_{P k}=\{C A s\}$ & \\
\hline Interaction measure & FFs relevance & Design coupling & Physical interaction & \\
\hline Modular structure & $\mathrm{N} / \mathrm{A}$ & Topological structure (Solution principle) & $\begin{array}{l}\text { Configuration structure } \\
\text { (Bill-of-material) }\end{array}$ & $\begin{array}{l}\text { Product } \\
\text { structure }\end{array}$ \\
\hline $\begin{array}{l}\text { Module identification } \\
\text { (decomposition) }\end{array}$ & $\begin{array}{l}\text { Pareto analysis } \\
\text { Qualitative classification }\end{array}$ & $\begin{array}{l}\text { Design matrix } \\
\text { decomposition (DMD) }\end{array}$ & $\begin{array}{l}\text { Interaction matrix analysis (IMA) } \\
\text { Modular function deployment } \\
\text { (MFD) }\end{array}$ & \\
\hline Concerns & Customer segmentation & Technological feasibility & Manufacturability & \\
\hline (2) Commonality & Functional commonality & Technical commonality & Physical commonality & \\
\hline Instances & $\begin{array}{l}\text { Values of customer requirements } \\
\mathrm{M}_{\mathrm{Fi}}^{*}=\left\{\mathrm{FFs}^{*} \mid \forall \mathrm{FF} \in \mathrm{M}_{\mathrm{Fi}}\right\}\end{array}$ & $\begin{array}{l}\text { TPs values of technical modules } \\
\mathrm{M}_{\mathrm{Tj}}^{*}=\left\{\mathrm{TPS}^{*} \mid \forall \mathrm{TP} \in \mathrm{M}_{\mathrm{Tj}}\right\}\end{array}$ & $\begin{array}{l}\text { CAs values of physical modules } \\
\mathrm{M}_{\mathrm{Pk}}^{*}=\left\{\mathrm{CAs}^{*} \mid \forall \mathrm{CA} \in \mathrm{M}_{\mathrm{Pk}}\right\}\end{array}$ & \\
\hline Similarity measure & $\begin{array}{c}\mathrm{d}_{\mathrm{q}, \mathrm{q}+1}=\sqrt{\sum_{\mathrm{p}=1}^{\mathrm{n}}\left(\mathrm{w}_{\mathrm{p}}\left(\frac{\mathrm{FF}_{\mathrm{p}, \mathrm{q}}^{*}-\mathrm{FF}_{\mathrm{p}, \mathrm{q}+1}^{*}}{\overline{\mathrm{FF}}_{\mathrm{p}}^{*}}\right)^{2}\right)} \\
\forall \mathrm{FF}_{\mathrm{p}, \mathrm{q}} \in \mathrm{M}_{\mathrm{Fi}}\end{array}$ & $\begin{array}{c}\mathrm{d}_{\mathrm{q}, \mathrm{q}+1}=\sqrt{\sum_{\mathrm{p}=1}^{\mathrm{n}}\left(\mathrm{w}_{\mathrm{p}}\left(\frac{\mathrm{TP}_{\mathrm{p}, \mathrm{q}}^{*}-\mathrm{TP}_{\mathrm{p}, \mathrm{q}+1}^{*}}{\overline{\mathrm{TP}}_{\mathrm{p}}^{*}}\right)^{2}\right)} \\
\forall \mathrm{TP}_{\mathrm{p}, \mathrm{q}} \in \mathrm{M}_{\mathrm{Tj}}\end{array}$ & $\begin{array}{l}U_{i j}=\frac{1}{\pi} \tan ^{-1}\left\{\alpha\left(D o S_{i j}+\beta\right)\right\}+0.5 \\
D o S_{i j}=\lambda \frac{F R_{i j}^{*}-F R_{i j}^{T}}{F R_{i j}^{*}} U_{i}=\prod_{j=1}^{n}\left(U_{i j}\right)^{w_{i j}}\end{array}$ & $\begin{array}{l}\text { Product } \\
\text { variants }\end{array}$ \\
\hline $\begin{array}{l}\text { Clustering analysis } \\
\text { Variants } \\
\text { (3) Integrateability }\end{array}$ & $\begin{array}{l}\text { Fuzzy C-Means clustering analysis (FCM) } \\
\left\{\mathrm{M}_{\mathrm{Fi}}^{\mathrm{V}}\right\} \\
\text { FF-TP mapping } \\
\text { Design matrix } \\
\text { Solution generation }\end{array}$ & $\begin{array}{l}\text { Fuzzy C-Means clustering analysis (FCM) } \\
\left\{\mathrm{M}_{\mathrm{Tj}}^{\mathrm{V}}\right\} \\
\text { TP-CA mapping } \\
\text { Manufacturability } \\
\text { Instantiation of technical modules based c }\end{array}$ & $\begin{array}{l}\text { Economic evaluation (U-C Plot) } \\
\left\{\mathrm{M}_{\mathrm{Pk}}^{\mathrm{V}}\right\}\end{array}$ & Integration \\
\hline
\end{tabular}


Jianxin Jiao and

Mitchell M. Tseng

Fundamentals of product

family architecture

Integrated Manufacturing

Systems

11/7 [2000] 469-483 leading companies have recognized that the formation of product families must have full representation of these three different perspectives. However, this is a very challenging task to make these three seemingly divergent perspectives coherent. Part of the reasons is because the knowledge about these different perspectives resides in different organizations. Due to lack of a systematic approach, these three different perspectives have been traditionally treated independently, if not fragmented.

Consequently, the goal of unifying sales, marketing, design and manufacturing through an integrated product family architecture is well-accepted, yet the achieving of this goal is often illusive. Without understanding their underpinning inter-relationship, product family portfolios could be created as a result of temporary "quick fix". It normally fails to bring in the benefits of product family or to stop the explosive growth of variety.

With clear understanding of fundamental issues underlying a PFA, a well-developed PFA can provide a generic architecture to capture and utilize commonality, within which each new product instantiates and extends so as to anchor future designs to a common product line structure. The rationale of the PFA resides with not only unburdening the knowledge base from keeping variant forms of the same solution, but also modeling the design process of a class of products that can widely variegate designs based on individual customization requirements within a coherent framework. Therefore, the PFA can perform as a unifying integration platform to synchronize market positioning, commonality employment and manufacturing scale of economy across the entire product realization process.

\section{Notes}

1 The terms module and building block are often used interchangeably. They are also called chunks (Pimmler and Eppinger, 1994). This term is attaining some popularity within major US manufacturing firms (Ulrich and Eppinger, 1995)

2 Views are equivalent to the domains of design. The purpose of using views instead of domains is to highlight the emphasis of product modeling in developing product family architecture, rather than exploring the design process itself.

3 Functional features are defined as a minimum set of independent features that completely characterize the functional needs of a product design in the functional domain.

4 Technical parameters are key variables that characterize the technological solution (product technology) created by the design process to fulfill the functional features. Major concern from the behavioral view involves technological feasibility.

5 Components/assemblies constitute the physical structure of a designed product. They are physical entities resulting from the design process to implement a technological solution/product technology for a set of functional features. In other words, CAs are the instantiations of technological solutions/ product technologies as a result of considering manufacturability and process capabilities.

6 By design coupling, we refer to the dependence between TPs in fulfilling a set of FFs. That is, the degree of unconditional and non-removable interactions between TPs with respect to FFs (Johannesson, 1997). Johannesson (1997) names this type of coupling as functional coupling.

\section{References}

Alexander, C. (1964), Notes on the Synthesis of Form, Harvard University Press, Cambridge, MA.

Anderson, D.M. (1997), Agile Product Development for Mass Customization, Irwin Professional Pub., Chicago, IL.

Andreasen, M.M. (1992), "Designing on a 'Designer's Workbench' (DWB)”, Proceedings of the 9th WDK Workshop, Rigi, Switzerland.

Baker, M. (1989), "Marketing: a new philosophy", The Quarterly Review of Marketing, Vol. 14, pp. 1-4.

Choi, S.C. and Desarbo, W.S. (1994), "A conjointbased product designing procedure incorporating price competition", Journal of Product Innovation Management, Vol. 11, pp. 451-9.

Choi, S.C., Desarbo, W.S. and Harker, P.T. (1990), "Product positioning under price competition”, Management Science, Vol. 36, pp. 175-99.

Dixon, J.R., Duffy, M.R., Irani, R., Meunier, K. and Orelup, M. (1988), "A proposed taxonomy of mechanical design problems", Proceedings of ASME Computers in Engineering Conference, pp. 41-6.

Erens, F. and Verhulst, K. (1997), "Architectures for product families”, Computers in Industry, Vol. 33, pp. 165-78.

Erixon, G. (1996), "Design for modularity", in Huang, G.Q. (Ed.), Design for X-Concurrent Engineering Imperatives, Chapman \& Hall, New York, NY, pp. 356-79.

Erixon, G., von Yxkull, A. and Arnstrom, A. (1996), "Modularity - the basis for product and factory reengineering", Annals of the CIRP, Vol. 45, pp. 1-6.

Erlandsson, A., Erixon, G. and Ostgren, B. (1992), "Product modules - the link between QFD and DFA", The International Forum on Product Design for Manufacture and Assembly, Newport, RI.

Feitzinger, E. and Lee, H.L. (1997), "Mass customization at Hewlett-Packard: the power 
Jianxin Jiao and

Mitchell M. Tseng

Fundamentals of product

family architecture

Integrated Manufacturing

Systems

$11 / 7$ [2000] 469-483 of postponement", Harvard Business Review, Vol. 75, pp. 116-21.

Fujita, K. and Ishii, K. (1997), “Task structuring toward computational approaches to product variety design”, Proceedings of ASME Design Engineering Technical Conferences, DETC97/ DAC-3766, Sacramento, CA.

Green, P.E. and Srinivasan, V. (1978), "Conjoint analysis in consumer research: issues and outlook", Journal of Consumer Research, Vol. 5, pp. 103-23.

Hatley, D.J. and Pirbhai, I.A. (1987), Strategies for Real-Time System Specification, Dorset House, New York, NY.

Henderson, R.M. and Clark, K.B. (1990),

"Architecture innovation: the reconfiguration of existing product technologies and the failure of established firms”, Admistrative Science Quarterly, Vol. 35, pp. 9-30.

Hillstrom, F. (1994), “Applying axiomatic design to interface analysis in modular product development", Proceedings of ASME 1994 Conference on Advances in Design Automation, ASME, DE-Vol. 69 No. 2, pp. 363-71.

Hubka, V. and Eder, W.E. (1988), Theory of Technical Systems, Springer-Verlag, Berlin, Heidelberg.

Hundal, M.S. (1990), “A systematic method for developing function structures, solutions and concept variants", Mechanisms and Machine Theory, Vol. 25, pp. 243-56.

Ishii, K., Juengel, C. and Eubanks, C.F. (1995a), "Design for product variety: key to product line structuring”, Proceedings of Design Engineering Technical Conference, ASME, DEVol. 83, pp. 499-506.

Ishii, K., Lee, B.H. and Eubanks, C.F. (1995b), "Design for product retirement and modularity based on technology life-cycle", Manufacturing Science and Engineering, MED-Vol. 2-2/MH-Vol.3-2, ASME, pp. 921-33.

Jiao, J. (1998), "Design for mass customization by developing product family architecture", $\mathrm{PhD}$ Thesis, Department of Industrial Engineering \& Engineering Management, The Hong Kong University of Science \& Technology.

Johannesson, H.L. (1997), “Application of interaction and functional coupling rules in configuration design", Proceedings of ASME Design Engineering Technical Conferences, DETC97/DTM-3869, Sacramento, CA.

Karmarkar, U.S. and Kubat, P. (1987), "Modular product design and product support", European Journal of Operational Research, Vol. 29, pp. 74-82.

Kohlhase, N. and Birkhofer, H. (1996), "Development of modular structures: the prerequisite for successful modular products", Journal of Engineering Design, Vol. 7, pp. 279-91.

Kotler, P. (1989), "From mass marketing to mass customization”, Planning Review, Vol. 17, pp. 10-13.
Kusiak, A. and Huang, C.C. (1996), "Development of modular products", IEEE Transactions on Components, Packaging, and Manufacturing Technology, Part A, Vol. 19, pp. 523-38.

Lanner, P. and Malmqvist, J. (1996), “An approach towards considering technical and economic aspects in product architecture design", Proceedings of the 1st International NordDesign Seminar on Engineering Design, Espoo, Finland, pp. 28-30.

Lu, S.C.-Y. (1990), “Knowledge processing for concurrent engineering: an evolving challenge in CIM research", Robotics and Computer-Integrated Manufacturing, Vol. 7, pp. 263-77.

Martin, M.V. and Ishii, K. (1996), "Design for variety: a methodology for understanding the costs of product proliferation", Proceedings of the 1996 ASME Design Engineering Technical Conferences, DTM-1610, Irvine, CA.

Martin, M.V. and Ishii, K. (1997), "Design for variety: development of complexity indices and design charts", Proceedings of 1997 ASME Design Engineering Technical Conferences, DFM-4359, Sacramento, CA.

Meyer, M.H. (1997), "Revitalize your product lines through continuous platform renewal", Research-Technology Management, Vol. 40, pp. 17-28.

Meyer, M.H. and Utterback, J.M. (1993), "The product family and the dynamics of core capability", Sloan Management Review, Vol. 34, pp. 29-47.

Mistree, F., Smith, W.F. and Bras, B.A. (1993), “A decision-based approach to concurrent engineering”, in Paresai, H.R. and Sullivan, W. (Eds.), Handbook of Concurrent Engineering, Chapman \& Hall, New York, NY, pp. 127-58.

Nagel, L.W. (1975), SPICE2: A Computer Program to Simulate Semiconductor Circuits, Memorandum ERL-M520, Electronics Research Laboratory, College of Engineering, University of California at Berkeley, Berkeley, CA.

Newcomb, P.J., Bras, B. and Rosen, D.W. (1997), "Implications of modularity on product design for the life cycle", Proceedings of ASME Design Engineering Technical Conferences, DETC96/DTM-1516, Irvine, CA.

Page, A.L. and Rosenbaum, H.F. (1987), "Redesigning product lines with conjoint analysis: how sunbeam does it", Journal of Product Innovation Management, Vol. 4, pp. 120-37.

Pahl, G. and Beitz, W. (1996), Engineering Design: a Systematic Approach, Springer, London.

Pimmler, T.U. and Eppinger, S.D. (1994),

"Integration analysis of product decompositions", Proceedings of ASME Design Theory and Methodology Conference, DE-Vol. 68, pp. 343-51.

Pine, B.J. (1993), Mass Customization: The New Frontier in Business Competition, Harvard Business School Press, Boston, MA. 
Jianxin Jiao and

Mitchell M. Tseng

Fundamentals of product

family architecture

Integrated Manufacturing

Systems

11/7 [2000] 469-483
Prasad, B. (1996), Concurrent Engineering Fundamentals, Prentice-Hall, Englewood Cliffs, NJ.

Sanderson, S.W. (1991), "Cost models for evaluating virtual design strategies in multicycle product families", Journal of Engineering and Technology Management, Vol. 8, pp. 339-58.

Sanderson, S. and Uzumeri, M. (1995), "Managing product families: the case of the Sony walkman”, Research Policy, Vol. 24, pp. 761-82.

Simpson, T.W., Chen, W., Allen, J.K. and Mistree, F. (1996b), "Conceptual design of a family of products through the use of the robust concept exploration method", 6th AIAA/USAF/NASA/ISSMO Symposium on Multidisciplinary Analysis and Optimization, Bellevue, WA, pp. 1535-45.

Simpson, T.W., Rosen, D., Allen, J.K. and Mistree, F. (1996a), "Metrics for assessing design freedom and information uncertainty in the early stages of design", Proceedings of ASME Design Engineering Technical Conferences and Computers in Engineering Conference, Irvine, CA, 96-DETC/DTM-1521. Suh, N.P. (1990), The Principles of Design, Oxford University Press, New York, NY.
Suzue, T. and Kohdate, A. (1990), Variety Reduction Program: A Production Strategy for Product Diversification, Productivity Press, Cambridge, MA.

Traister, J.E. (1997), Handbook of Electrical Design Details, McGraw-Hill, New York, NY.

Tseng, M.M. and Jiao, J. (1996), "Design for mass customization", Annals of the CIRP, Vol. 45, pp. 153-6.

Ulrich, K. (1995), "The role of product architecture in the manufacturing firm", Research Policy, Vol. 24, pp. 419-40.

Ulrich, K.T. and Eppinger, S.D. (1995), Product Design and Development, McGraw-Hill, New York, NY.

Ulrich, K.T. and Seering, W.P. (1990), "Function sharing in mechanical design”, Design Studies, Vol. 11, pp. 223-34.

Ulrich, K. and Tung, K. (1991), "Fundaments of product modularity", in Sharon, A. (Ed.), Issues in Mechanical Design International 1991, ASME, New York, NY, DE-39, pp. 73-79.

Wheelwright, S.C. and Clark, K.B. (1992), "Creating project plans to focus product development", Harvard Business Review, Vol. 70, pp. 70-82

Wheelwright, S.C. and Sasser, W.E. (1989), "The new product development map", Harvard Business Review, Vol. 67, pp. 112-25. 